\title{
PRESIDENTIAL ADDRESS THE FUTURE OF NEW ZEALAND FARMING
}

\author{
RUSSELL HURST \\ Invernia Holdings, 4 KRD, Oamaru
}

My first contact with the NZ Grassland Association was in 1996 when I was asked to convene the organizing committee for the Oamaru Conference.

I soon found that the Grassland Association was a great mix of farmers, researchers, industry advisors and scientists.

To me AgResearch Grasslands at Palmerston North is the home of pastoral research in NZ and with the conference here in Palmerston North it will be a great opportunity to see where it all happens.

On looking back at the presidential addresses over the past 10 years the common theme is that agriculture is the backbone of the NZ economy. I believe that is still the case and will be in the future. The major threats to agriculture are not new industries developing but agriculture being driven out by bureaucracy. The Resource Management Act, Occupation Safety and Health, Employment Relations Act, local government reform bill, health and safety in employment act and all others put tremendous compliance pressures on business. These acts are not specific to agriculture. They affect all businesses both large and small.

I am not against these acts and regulations but in many cases common sense has been forgotten. In moderation they are workable but if overdone they can cause problems and extra expense for no return.

As farmers we are at the beginning of the production line and have limited ability to pass on the compliance costs associated to many of these acts.

A number of years ago all local and regional governments were restructured to improve efficiency. We now find that in almost every town and city the local council will be in the top 10 for the number of people employed and many are in the top 5.

Years ago the unemployed used to go to the railways to fill in their day and collect their pay. Now they go to their local government. The majority of these people are what I call unproductive. Their main tasks are to police central government policies.

It is time we, the ratepayers of NZ, have a rate revolt and stop paying these people and get some commonsense policies put back in place by practical people.

Compliance costs, levies and taxes are all extra expenses that are eating away at the profit of farmers. When the indirect costs such as time spent administrating these are added on, the true cost is immense. The proposed flatulence tax is a classic example.

It is proposed that the meat and dairy companies will collect this tax but will they get paid by the government for doing so or do they reduce what they pay the farmer for his stock to cover their costs. I suggest that it will be the latter in which case the farmer is paying twice.

The Government got us into the Kyoto Protocol therefore they must be responsible for funding its associated costs.

Education is another area where agriculture is missing out. All too often we hear of careers advisors at schools advising students to stay away from agriculture unless they can not get anything else. They seem to miss the fact that a good 18 year old school leaver can earn between \$25-30000 with no experience and no responsibility on a dairy farm and within 6-7 years can have assets in excess of half a million dollars. It is hard to find other careers where young people can start with nothing and regularly build up large assets in such a short time.

Our universities are also lacking agricultural students and the number of New Zealanders doing post graduate agricultural degrees is at an all time low.

Agriculture needs agricultural students to provide knowledge in the service industries and research development areas. If we don't continue with the high standard of research we have had in the past then we will very quickly loose the competitive advantage New Zealand has to other countries.

As the world's population continues to grow and the available area of productive land decreases new technology has to be developed and used to feed the growing population.

I believe it is time to change who runs this country. We need strong practical people with commonsense. It is time the state took back ownership of essential services; i.e. power, telephone, roading, railways, hospitals and education. We have proved that private enterprise or state owned entities don't work with essential services. 
The government has already had to bail out Air New Zealand and the railways. Recently we have suffered power shortages because the power generation companies have been too focused on profit and have not been doing froward planning.

The proposed Project Aqua power development on the Waitaki River is a classic example of a State owned enterprise being totally profit focused and not looking at the wider community.

Meridian wants to take $73 \%$ of the water from the Waitaki River to generate power and leave very little for other future uses.

If the government was to take control of Meridian and do the development in conjunction with present and future proposed irrigation schemes then everyone in the wider community could benefit, as well as the nation with more power and more agricultural production. Free enterprise must be encouraged and must be able to compete in these essential services but I believe the state must play a major part in the control and operation of these essential services so that long term forward planning can be done for the benefit of all New Zealanders.

I would like to thank the members of the executive for their time and very positive contributions they have all made during the year. They have made my job very easy.

I would like to make special thanks to Derek Woodfield for his contributions over the many years he has been associated with the Association and especially this year for convening the Conference organising committee. 